\title{
Dialectical Behaviour Therapy as a treatment for Borderline Personality Disorder in prisons: three illustrative case studies
}

To appear in press with the Journal of Forensic Psychiatry and Psychology (2007) 18.

\section{Claire Nee* and Sarah Farman}

International Centre for Research in Forensic Psychology

University of Portsmouth, UK.

Corresponding author:

Claire Nee PhD

Director

International Centre for Research in Forensic Psychology

Department of Psychology

University of Portsmouth

King Henry Building

King Henry $1^{\text {st }}$ St

Portsmouth

PO1 2DY

Sarah Farman, MSc in Forensic Psychology.

Word count minus references and abstract: 6,303 


\title{
DBT as a Treatment for BPD in prisons: three illustrative case studies
}

\begin{abstract}
Little is known about the effectiveness of treatments for severe personality disorder in prisons. Any treatment within the prison context will aim to reduce criminogenic risk in its participants, as well as ameliorate the overall symptomatology of the disorder. The over-representation of Borderline Personality Disorder in female prisons has lead to pilots of Dialectical Behaviour Therapy in three such establishments in the UK. This treatment was designed for borderline personality disordered women in the community in the USA and this is the first time it has been piloted within a UK prison context. It was treatment of choice as it had the strongest evidence base in lower security settings. Overall findings from the pilots have been very promising in terms of the viability of DBT as an offending behaviour programme and improving the manageability of prisoners on the wing. The case studies described here aim to illustrate in some detail the cognitive and behavioural change process in individuals over a year of treatment, plus six months follow-up, and to highlight the particular challenges faced by participants and therapists when delivering treatment in prison. By showing improvements in all three cases, which vary in terms of current symptomatology and background, we aim to demonstrate the versatility of DBT in the prison setting and its capacity for reducing criminogenic risk.
\end{abstract}

Key words: DBT, BPD, prisons, interventions, women offenders, what works.

\section{INTRODUCTION}

Little published evidence exists regarding 'what works' in the treatment of severe personality disorder in high-security settings. This applies to the entire mother-tongue English speaking world, despite calls to the contrary in recent years (e.g. Warren et al, 2003). Less attention is devoted specifically to female offenders, despite a growing prison population on both sides of the Atlantic (Home Office, 2005; Bloom et al, 2004). Within this population lies a considerable over-representation of female prisoners with borderline personality disorder (BPD), estimated at $20 \%$ in the UK as opposed to $2 \%$ in the general population (Singleton et al, 1998) with similar patterns in New Zealand (Department of Corrections, 1999) and the U.S. (Berzins and Trestman, 2004; Diamond et al, 2001). We briefly review the limited but growing evidence for Dialectical Behaviour Therapy (DBT, Linehan, 1993 a,b) as the current treatment of choice for BPD and then present three case studies from recent UK prison pilots of the treatment. 
Links have been suggested between BPD and criminogenic risk (Coid, 1993; Jones, 2001; Nee and Farman, 2005; Raine, 1993). The features of $\mathrm{BPD}^{1}$ undoubtedly make these offenders difficult to manage, treat, and at high risk of re-offending. However, only recently has a concerted attempt been made to address their needs in the UK and Canada $^{2}$.

Evidence is accruing in the low security setting for DBT as an effective treatment for BPD. Hayes et al, (2004), reviewing 15 studies, including seven randomised controlled trials, noted 'DBT is clearly the best empirically validated psychosocial treatment currently available for BPD' (p.15). A small but growing body of evidence is also emerging in high security settings for both improvement of the overall syndrome and reducing criminogenic risk (Nee and Farman, 2005). This is good news for the Dangerous and Severe Personality Disorder (DSPD) ${ }^{3}$ programme in the UK, where clearly emphasis should be on reducing risk as well as on treatment (Maden et al, 2004).

DBT is a cognitive behavioural therapy underpinned by classical and Eastern philosophies, developed by Linehan (1993 a,b) to address the problems of those diagnosed with BPD in community settings. Over the course of Linehan's extensive career as a clinician she has come to the view (and quotes supportive empirical research (Linehan, 1993a)) that emotional vulnerability coupled with an invalidating environment from caregivers are high risk factors for developing the emotion dysregulation fundamental to BPD. Standard one-year programmes involve weekly group skills sessions incorporating one of four modules: core mindfulness; interpersonal effectiveness; emotion regulation; and distress tolerance; plus a weekly one-to-one therapy session. Core mindfulness is fundamental to the programme and incorporates Eastern mindfulness practices. The central dialectic in DBT is that of acceptance versus change. Patients diagnosed with BPD have great difficulty in accepting themselves and others, and DBT leads to the development of acceptance skills as well as the change skills typically seen in CBT. 
Extra features in DBT considered essential by Linehan (1993a) include: the longer than typical intervention period plus individual therapeutic support; addressing 'therapy interfering' behaviours (any behaviour which undermines the therapeutic relationship); weekly delivery team consultation to ensure programme integrity and support; and 24-hour telephone access to a therapist for participants in times of crisis.

DBT was the treatment of choice in two recent sweeps of pilots in UK prisons because of its grounding in CBT (and CBT's evidence-base with offenders (Lipsey, 1995)) plus promising findings from lower security settings. The overall findings showed clear potential for the effective delivery of DBT in prison settings (Nee and Farman, 2005). The aim of presenting case studies from the pilots here is to provide a richer illustration of the complex profiles of women prisoners with BPD and the extra level of challenge that treatment faces when delivered under the operational constraints of the prison setting, in comparison to individuals in the community, and how these impact on therapy.

\section{Empirical evidence for the treatment of BPD}

There are currently seven published studies on the treatment of BPD using DBT in low security in-patient and out-patient settings, six of which involve randomised controlled trials (Linehan et el, 1991; Linehan et al, 1993; Linehan et al, 1994; Linehan et al, 1999; Bohus et al, 2000; Koons et al, 2001; Verheul et al, 2003). Sample sizes ranged from 20 to 58. All participants were women and five out of six studies involved the standard year-long DBT programme. All showed statistically significant improvements, (sustained at follow-up for two studies, Linehan et al., 1993; Linehan et al., 1999) on psychometric outcomes and parasuicidal behaviour, with significantly fewer in-patient days and lower attrition than treatment as usual.

Four studies exist in the high security setting. Low et al, (2001a) looked at standard DBT in a high-security special hospital and noted a significant reduction in self-harm, dissociation, survival and coping beliefs, suicidal ideation, impulsivity and depression, maintained at six-month follow-up. Case studies were also published, reflecting these findings in greater detail (Low et al, 2001b). A qualitative study of DBT in four women's facilities in Canada (Sly and Taylor, 2003) showed good preliminary results, but we await a quantitative evaluation. 
Nee and Farman, (2005) published an evaluation of the first run of UK female prison pilots. Two standard, one-year programmes were included, a 16-week programme and a waiting list control group. Despite considerable challenges in the delivery of DBT, the standard programmes saw statistically significant improvements in their participants $^{4}$, sustained at six-month follow-up on psychometrics linked with criminogenic risk, with no significant change in the control group. An overall downturn in self-harm was noted in DBT participants at all three pilot sites, suggesting that DBT was a viable intervention in this context.

Other new treatments for BPD in clinical settings are now emerging and published descriptions are becoming available, such as Cognitive Analytical Therapy (Ryle, 1997, 2004, and Manual Based CBT (Tyrer et al, 2004). None have been robustly evaluated as yet other than Mentalisation Based Treatment (MBT) for which an RCT exists, plus a 16-month follow-up (Bateman and Fonagy, 2004, 1999). MBT formulates BPD as an attachment disorder resulting in the inability to mentalise ${ }^{5}$. The clinically-based evaluation showed very promising, statistically significant improvements, further enhanced at follow-up. In the current absence of other evidence in the high-secure setting however, we are compelled to concur with Warren et al (2003) and Hayes et al (2004) that DBT at present shows the most promise in treating borderline personality disorder that has resulted in serious offending behaviour.

\section{METHOD}

\section{Participants}

Cases were drawn from closed training prisons delivering the standard one-year programme. Inclusion criteria were: a SCID-II diagnosis of BPD; a history of suicidal or parasuicidal behaviour; and a future serious offence risk. Cases selected varied in terms of the extent of the current disorder, childhood background and experience, and level of success on outcome measures, so as to show a range of applications for DBT. Written informed consent was obtained for two of the cases specifying exactly how their data would be used. The third case was untraceable, and so key identifiable 
features of her case (such as index offence, age etc.) were changed in order to make her unrecognisable.

\section{Treatment}

DBT was preceded by 'orientation' ${ }^{6}$. The programme then consisted of a weekly onehour session of individual therapy and one weekly two-hour session of group skills training. Individual therapy focussed on the Stage $1^{7}$ DBT treatment hierarchy. Target problem behaviours, recorded on daily individual diary cards were examined in individual therapy, using behavioural chain analyses and solution analyses. An answerphone system $^{8}$ was set up in place of 24-hour telephone consultation.

\section{Assessment Measures}

Participants were assessed pre, mid, post and six-months post-DBT using a battery of 10 psychometric tests. No standardised measure of risk of re-conviction exists as yet for this population and many severely personality-disordered offenders serve very long sentences with a proportion that are never released. Therefore, psychometric measures strongly associated with criminogenic risk were of particular importance here. Impulsivity (Robinson, Porporino and Beal, 1998), locus of control (Walters and White, 1989), self-esteem (Ross and Fabiano, 1985) and emotion control (Roger, 1997) have been strongly linked with increased risk in previous research ${ }^{9}$, so measures of these, alongside a global measure of the overall BPD syndrome and dissociation were included, plus measures of suicidal ideation. Recorded self-harm and adjudications ${ }^{10}$ data were also collected at the four time points. For each case, we report the key psychometrics indicating change, behavioural measures, and findings based on interviews at the four time points with the participants, their individual therapists, group skills tutors and their case files.

\section{RESULTS}




\section{Case Study 1: Ms A}

26-year-old Ms A was a serving a six-year sentence for attempted murder.

\section{Brief History}

One of four siblings, Ms A was taken into care at the age of five when her parents separated. Ms A spent three years in children's homes, until she was fostered by a family from the age of 8 to15. Problems with anger control culminated in three further moves to foster homes between the age of 15 and 16. Due to hearing problems at birth Ms A was unable to speak until she was six years old. Her speech impairment, hearing problems, separation from her natural parents and siblings and a childhood devoid of affection resulted in a sense of abandonment and isolation.

Ms A had two recorded incidents of sexual abuse during childhood and a history of severe alcohol misuse during her teenage years. She had continual difficulties with interpersonal relationships, and fire-setting behaviour from the age of 11 . She had 10 previous convictions for harassment.

\section{Self-Harming History and Presenting Problems}

Ms A's self-harming behaviours began at age 8 and included scratching, punching and cutting herself. Ms A made three suicide attempts when she was 16 and a further two between the age of 20 and 22 .

\section{Initial Assessment}

A SCID II interview indicated Ms A met six of the criteria for BPD, namely: identity disturbance; impulsivity; recurrent self-mutilating behaviour; affective instability; chronic feelings of emptiness and transient, stress-related paranoid ideation. She also met criteria for depressive personality disorder and SCID I criteria for major depressive disorder and anorexia nervosa. Initial scores on assessment measures for DBT (see Table 1, Time 1) revealed, in particular, a high overall borderline symptomatology (Borderline Syndrome Index score), strong emotion dysregulation, high impulsiveness and 'state anger' (intensity of angry feelings). 
Primary targets included reducing parasuicidal behaviour; suicidal tendencies and disturbed eating patterns, and to reduce the following TIBs (therapy-interfering behaviours): being non-verbal in group therapy and resisting agenda setting. Reducing the quality of life-interfering behaviours around relationship difficulties were also targets. Secondary targets included increasing emotion modulation; decreasing selfinvalidation and decreasing the mood dependency of her behaviour.

\section{Intervention}

Ms A was judged to be highly internally motivated to decrease her self-harm throughout DBT, to leave prison and to no longer be a danger to society. She attended 95\% of group skills training sessions and her individual therapy. A repetitive cycle emerged in therapy, beginning with self-harm and/or suicidal thoughts, followed by an increase in behavioural skills (particularly using 'distress tolerance' see below) and a decrease in self-harm and/or suicidal thoughts. This was accompanied by a disrupted eating pattern and a strenuous exercise plan. Therapy would then focus on disruptive eating. At this point Ms A would comfort eat, refrain from exercise and the cycle would begin again. Ms A was very dependent on this type of control-release mechanism.

\section{Key stages}

A key stage was reached for Ms A at the mid-point of the programme when she became actively involved with the group, accompanied by much self-disclosure. Ms A gained insight into her behavioural patterns (including the control-release cycle applied to eating and fire-setting) and was more open to appreciate where cognitions and behaviours fitted in.

\section{Key stressors}

During DBT Ms A re-established contact with her biological brother after many years. Being incarcerated resulted in increased tension around this relationship. Although unfulfilling and distressing, Ms A learnt control in her relationships due to this, using core mindfulness skills. Prison staff also reported that Ms A became more willing to interact with them as DBT continued. 
Throughout DBT therapists noted and Ms A reported using many skills, with real assimilation occurring around the mid-point when the repeat of the programme began. Ms A began to use core mindfulness skills (particularly 'observe and describe ${ }^{11}$ ) on a more-or-less daily basis. Chain analysis during individual therapy helped her identify early triggers to negative cognitions and behaviours and when experiencing intense emotions or urges to self-harm Ms A would distract herself using 'self-talk' and 'pro's and con's from the distress tolerance module, and would go to the gym, dance in her cell, write poetry or draw pictures. Skills from the emotion regulation module were used much less frequently.

\section{Psychometrics}

Table $1^{12}$ indicates Ms A's notable improvements in the Borderline Syndrome Index, dissociative experiences, impulsivity, state anger, self-esteem, locus of control, survival and coping beliefs and emotional rehearsal pre-DBT to six-months postDBT, with the most dramatic change at the six-month stage. Trait anger, emotional inhibition and aggression control scored favourably at all time points. Inward anger and child-related concerns remained problematic at the four time-points.

\section{Table 1 here.}

\section{Behavioural Data}

Figure 1 shows that in the six-months pre-DBT Ms A had ten self-harm incidents, mostly involving cutting. After seven incidents near the beginning of DBT (representing an 'extinction burst' (Linehan, 1993a)), Ms A had only one other incident of self-harm in the entire 12-months of the programme. This involved burning and was triggered by the imminent programme end. During the last three months of the six-month follow-up period Ms A had seven incidents of self-harm (all cutting) and one suicide attempt which coincided with her learning of her imminent move to another prison. In comparison to Ms A's self-harm pre-DBT, however, these incidents were of lower lethality ${ }^{13}$.

\section{Figure 1 here}

Pre-DBT Ms A had one adjudication for fire setting and was on a standard regime (the mid-level of a prison's incentives and earned privileges scheme). Throughout 
DBT and the six-month follow-up period Ms A had no adjudications and was raised to enhanced regime (the highest level).

\section{Discussion}

Ms A presented as an uncommonly problematic case. With a history of neglect, sexual abuse and disabilities, she had the strongest BPD symptomatology of our three cases, plus co-morbid diagnoses of depression, anorexia nervosa and a history of alcohol misuse. Her profile included very disturbed and chronic self-harming behaviour from early childhood. Her antisocial behaviour comprised a long history of fire-setting behaviour and harassment which began in her early teens. Despite this exceptional profile, Ms A made significant strides during this first year of therapy and showed considerable commitment. On primary targets, her parasuicidal behaviour and suicidal tendencies decreased. While it was uncertain as to whether change was achieved in disturbed eating, her new insight into her control-release cycle was seen as a very positive achievement, with further work needed. She became verbal in group settings, with further work needed on agenda setting. In relation to life-interfering behaviours, she showed an improvement in interpersonal interactions and increased control of relationships with individuals inside and outside of the prison environment. For her secondary targets, Ms A showed an increase in emotion modulation and a decrease in self-invalidation and mood dependency behaviour towards the end of DBT through the daily use of her behavioural skills and the validation she received in therapy and increasingly on the prison wing. The achievements in the year's treatment were reflected in considerable positive changes in her psychometrics and self-harm, improving her quality of life, manageability and criminogenic risk.

The case highlights the impact DBT can begin to have on deeply ingrained cognitions (e.g. Ms A had felt abandoned and isolated from the age of five) and behaviours (e.g. Ms A had been self-harming since the age of eight) in a relatively short period of time. However, due to the severity of past invalidating environments and accompanying dysfunctional coping strategies, it also emphasises the need for therapy to continue beyond the initial year of DBT and thus the client's internal motivation to change is very important if progress is to occur. Ms A's increase in self-harm during the follow-up period indicates the need for continuing support and therapy. This was a clear finding from the pilots as a whole (Nee and Farman, 2005) and previous 
commentators (Low, Jones, Duggan, MacLeod \& Power, 2001; Linehan, 1993a) have noted that women with such severe and multiple problems as these are likely to need more than one year's intervention to maintain progress and fully address posttraumatic distress, for example.

Ms A (and her therapists) felt her improvements were related to the use of core mindfulness and distress tolerance skills) but strongly voiced her need for further support.

\section{Case Study 2: Ms B}

Ms B, aged 19 years, was serving an eight and a half year sentence for attempted murder. She had one previous conviction for theft.

\section{Brief History}

Ms B had experienced physical abuse and humiliation by her stepfather from age three, sexual abuse from her father from age six to sixteen and was raped by an unknown perpetrator at 16 . She had suffered emotional and physical abuse from her mother. She was bullied at school. Social services were involved from early on resulting in three problematic foster placements. In adolescence, Ms B became involved with violent intimates. Domestic violence was a feature in her relationship with her partner and co-defendant, though she still had close relationships with her two brothers and her maternal grandmother.

\section{Self-Harming History and Presenting Problems}

Ms B presented with a history of self-harming behaviours, mental health problems, substance misuse and relationship difficulties. She had long-standing visual hallucinations (since age three) and dissociative experiences (also since childhood). Self-harming (cutting and later tying ligatures) began when she was 11 years old alongside the presence of auditory hallucinations. She began misusing drugs at this time and drinking heavily from the age of 13 . She had been hospitalised several times following overdoses.

Ms B had little experience of appropriate relationships or insight into her own role in their development and maintenance. She had a number of unstable relationships in 
prison. Ms B depended heavily on the affirmation of others, having little sense of her own self-worth.

\section{Initial Assessment}

A SCID II assessment revealed that Ms B met criteria for borderline personality disorder. There was concern that on the initial DBT assessment measures at Time 1 (see Table 2) Ms B may have feigned overly positive responses. For example, Ms B reported no feelings associated with BPD on the Borderline Syndrome Index. Selfpreservation, fear, and a lack of understanding of the aim of the assessment questions were possible reasons for this, suggested by her therapist. Her main areas of concern were around dissociation and anger control which were borne out by her mid-DBT psychometric scores.

\section{Stage 1 Targets}

Primary targets included: to decrease parasuicidal behaviour and TIBs of outbursts of frustration, anger ${ }^{14}$; and hyperactivity ${ }^{15}$. To decrease quality of life-interfering behaviours: dependence on medication/substance misuse, relationship difficulties, impulsivity, anger and lack of sense of self-worth. To increase behavioural skills by: identifying and utilising appropriate skills to help cope more effectively with stressful situations, relationship difficulties, general interactions, and to challenge dysfunctional thoughts. Secondary targets were to decrease self-invalidation and to increase emotion control.

\section{Intervention}

Ms B attended all group skills training sessions and only missed two individual sessions in the entire year of the programme.

Through therapy Ms B gained an awareness and an understanding of the chain of events that led to her emotional dysregulation and the function of her urges to engage in self-destructive behaviour (i.e. self-harm, substance misuse, lashing out at property). During the second half of DBT, Ms B began to acknowledge that her self- 
destructive behaviour had been her only way of gaining control of her emotions preDBT.

Therapy focused on increasing the behavioural skills of emotion regulation. In particular 'PLEASE MASTER' ${ }^{16}$, was a key skill enabling Ms B to decrease her anger, as was being honest about her emotions with other people and allowing herself to cry. She found distress tolerance skills, particularly 'radical acceptance' invaluable, especially when dealing with family situations. Throughout DBT, Ms B's mother continued to invalidate her, reminding her that she would never change. Ms B radically accepted that she had a "seriously destructive relationship" with her mother and that she could not "make her be my mum." Ms B would then make a "wise mind' decision about what skills to use next (if necessary) to protect her from further negative emotions.

Interpersonal effectiveness skills became important in giving Ms B an insight into her role in the development and maintenance of relationships. Through therapy Ms B gained awareness of her over-dependence on dysfunctional relationships and refrained from forming any further inappropriate relationships. DBT also enabled Ms B to develop her own sense of self-worth decreasing her dependence on the affirmation of others.

Core mindfulness skills were used to take time out and calm down during urges to self-harm or periods of anger. 'Wise mind' was useful in helping Ms B take control. This was aided by weighing up both the short-term and the long-term 'pro's and con's' of particular behaviours. During the second half of DBT, core mindfulness skills began to underpin Ms B's progress, enabling her to stay in the moment and helping her to decrease the frequency of her dissociative experiences (see Table 2). She overlaid this foundation with a raft of distress tolerance and interpersonal effectiveness skills to address her drug dependency (her illicit substance misuse had transferred to a dependence on medication while incarcerated). Using 'pros and cons' to inhibit the early part of the behaviour chain, she then utilised interpersonal effectiveness skills to discuss and limit the medications she was taking with the prison 
doctor. Initially, this process caused an increase in auditory hallucinations and selfharm. However, through being mindful and remaining focused and determined, Ms B either stopped or decreased the levels of her medications.

\section{Key Stages}

The development of the therapeutic relationship was crucial to Ms B's progress in DBT (as emphasised by Linehan (1993a)). Ms B felt she had a strong, positive relationship with her individual therapist, a relationship that "was safe." Ms B's perception of her therapist as honest, trustworthy, and understanding of her problems enabled Ms B to open-up for the first time and encouraged problem solving.

\section{Key Stressors}

During the first half of DBT Ms B's younger brother came out of remission from cancer. She found this extremely distressing, which may explain the high levels of borderline symptomology, dissociative experiences and trait anger at the mid-DBT testing point (see Table 2). However, Ms B had very low levels of recorded self-harm at this time (see Figure 2). This suggests that Ms B was able to identify and utilise appropriate skills to help her cope more effectively with the situation.

Contact with Ms B's mother diminished considerably towards the end of DBT once Ms B realised its negative effects.

\section{Psychometric Data}

Table 2 shows from mid to post-DBT Ms B reported decreases in feelings associated with BPD (as measured by the Borderline Syndrome Index), trait anger and a dramatic decrease in dissociative experiences. She showed increases in self-esteem, locus of control and survival and coping beliefs as reasons for not committing suicide. Scores on impulsivity and state anger remained very low throughout. Comparison of the six-month's post-DBT psychometrics and the post-DBT psychometrics showed that Ms B's scores remained stable or showed a small deterioration.

Table 2 here

\section{Behavioural Data}


Figure 2 shows Ms B had 23 incidents of self-harm in the six-months pre-DBT; 21 incidents of self-harm during the first six-months of DBT and one month free of selfharm; 12 incidents of self-harm during the last six-months of DBT and four months free of self-harm; and 12 incidents of self-harm during the six-month follow-up period and two months free of self-harm. The majority of incidents involved cutting. Overall the frequency of Ms B's self-harming behaviour decreased during DBT in comparison to pre-DBT and continued to decrease during the six-month follow-up period. The lethality of Ms B's self-harm reduced considerably (from cutting to scratching).

Figure 2 here

Ms B used self-harm as a coping strategy to deal her relationship with her mother and her changes in medication. She seemed to cope more adaptively, however, with her brother's cancer, though she identified this as her greatest stressor during DBT.

Ms B had no adjudications prior to or throughout DBT. She had one non-violent adjudication for bad behaviour during the six-month follow-up period. Ms B was on an enhanced regime for the entire data collection period.

\section{Post-DBT}

After completing DBT Ms B continued to work on vulnerability factors. She successfully completed a Drug Rehabilitation and Drug Awareness Programme and became a peer support worker for prisoners on the Rehabilitation Mentoring Scheme. Increased confidence allowed Ms B to undertake a domestic violence course. PostDBT Ms B was chosen to represent the prison on a number of occasions including meeting Princess Anne and visiting a national gallery to see her own artwork displayed.

\section{Discussion}

Ms B's case included chronic physical, emotional and sexual abuse from a very early age and violent intimate relationships from adolescence onwards. As well as meeting the criteria for BPD, she had a history of substance misuse and hallucinations. Ms B made significant progress after one year of DBT on psychometric and behavioural measures, reducing her overall criminogenic risk. When incarcerated at age 17 for attempted murder, Ms B had only experienced a turbulent and traumatic way of life, and had long-standing dysfunctional thoughts (e.g. perceived negative judgements and negative self-perceptions) and maladaptive coping strategies, such as self-harm 
and substance misuse and dissociation. Despite her profile, she had not been diagnosed with BPD. However, because of her commitment to the programme, she began to meet her first-stage targets: she decreased her self-harming behaviour; addressed her substance misuse; addressed her relationship difficulties; and increased her sense of self-worth and self-confidence.

\section{Case Study 3: Ms C}

Ms C, aged 20 years, was serving a two and a half year life sentence for manslaughter. She had no other previous convictions.

\section{Brief History}

Ms C came from a large supportive family and was especially close to her father. She had a stable and loving childhood, but 'a difficult and odd type of adolescence'. At age 13 , the combination of being bullied at school and her father becoming seriously ill, resulted in $\mathrm{Ms} \mathrm{C}$ being taught by a home tutor and receiving professional counselling.

Ms $\mathrm{C}$ watched her father's condition deteriorate from age 13 to 17 when he died which she found extremely traumatic. Shortly after her father's death Ms C met her (male) victim who was a heavy drinker and a self-harmer. During the intimate relationship that followed Ms $\mathrm{C}$ began consuming excessive amounts of alcohol on a daily basis and self-harming.

At the time of her index offence Ms $\mathrm{C}$ had been drinking heavily, she was also taking anti-psychotic medication (for violent mood swings) and anti-depressants. Ms C had very little recollection of her victim's death due to her level of intoxication. She could give no reason why she carried out the offence, but accepted responsibility and expressed deep remorse.

\section{Self-Harming History and Presenting Problems}

Ms C's intimate relationship with her victim involved mutually destructive selfharming (cutting) behaviour and alcohol misuse, which began when Ms C was 17 years old as coping strategies to deal with the loss of her father. 
In the time leading up to the index offence, the frequency and lethality of Ms C's selfharming behaviour escalated leading to several suicide attempts. Ms C felt 'trapped' in her intimate relationship (Ms C's partner constantly threatened to kill Ms C or himself if she terminated the relationship) and to get relief from the feelings of depression, and the side effects of the anti-psychotics she was taking.

She presented with difficulties in controlling her anger when under the influence of alcohol.

\section{Initial Assessment}

Psychiatric court reports recorded that Ms C met criteria for borderline personality disorder. Initial scores on assessment measures for DBT revealed a less severe profile than for instance Ms A, though causes for concern were her scores for overall borderline symptomatology (BSI), impulsivity and dissociation (see Table 3, Time 1).

\section{Stage 1 DBT Targets}

Primary targets were to: decrease parasuicidal behaviour and quality of life-interfering behaviours: alcohol misuse, anger, depression. To increase behavioural skills by developing appropriate methods of coping with crises and managing emotions. Ms C was highly motivated from the start and had no notable therapy-interfering behaviours. Secondary targets included increasing self-validation, self-efficacy and emotion control.

\section{Intervention}

Ms C quickly gained an understanding of the chain of events that typically led to her emotional dysregulation (particularly connected to issues around abandonment) and parasuicidal urges, and how her thoughts and emotions impacted on her behaviour. From the outset Ms C attempted to practise all of the skills that were taught in the group sessions. She found that the hardest skills to master (such as 'radical acceptance' from distress tolerance) were the most effective in the long run.

Skills from core mindfulness were used to take time out, calm down and take control of emotions, thoughts and urges. Core mindfulness skills were usually chosen over 
skills from the other three modules, particularly 'one-mindfully' ${ }^{17}$ and "nonjudgementally ${ }^{18}$. As one of Ms C's targets was to control her anger she began to 'non-judgementally' observe the way of life on the wing, accept and acknowledge it, without participating in hostile interactions, as she would have in the past.

Interpersonal effectiveness skills were important in giving $\mathrm{Ms} \mathrm{C}$ an insight into the intimate relationship she had with her victim and thus also helped Ms C with her offence-related work. Her preferred emotion regulation skill was 'building MASTERy' from 'PLEASE MASTER' (see footnote 15) which she used on a daily basis to reduce her vulnerability to negative emotions by playing the guitar. She used distress tolerance skills as a quick fix or distraction technique (usually 'radical acceptance' and 'pro's and cons'), but would work on the problem aided by skills from the other three modules. This would prevent a spiral into self-harm if she was, for instance, enduring the long delay between delivery of a parcel to the prison and her receiving it, which happened regularly. 'Pro's and cons' allowed her to weigh up both the short-term and the long-term consequences of her potential actions on a daily basis.

\section{Key Stages}

A key stage for Ms C was when mindfulness became a way of life for her, at around three months into DBT. At this time, she also began to attend weekly Buddhist meetings at the prison, and practised mindfulness and meditation on a daily basis.

\section{Key Stressors}

Ms C had no key stressors during her time on DBT.

\section{Psychometric Data}

Table 3 shows the dramatic decreases in feelings associated with BPD (Borderline Syndrome Index), dissociative experiences, and impulsivity reported by Ms C from pre-DBT to six-months post-DBT. She showed a notable increase in self-esteem, internal locus of control and survival and coping beliefs as reasons for not committing suicide. Scores on state and trait anger remained relatively low. 


\section{Table 3 here}

\section{Behavioural Data}

Figure 3 shows Ms C had four recorded incidents of self-harm in the six-months preDBT (all incidents involved cutting) and no incidents of self-harm during the 12 months of DBT or during the six-month follow-up period. Ms C's urges to self-harm decreased and eventually stopped over the course of DBT.

\section{Figure 3 here}

Ms C had one non-violent adjudication pre DBT (unauthorised drug), one non-violent adjudication during DBT (disobeying a lawful order) and one non-violent adjudication for an unauthorised possession during the six-month follow-up period. Ms C was on an enhanced regime for the entire DBT period.

\section{Post-DBT}

Post-programme, Ms $\mathrm{C}$ has done a considerable amount of work addressing her history of alcohol misuse through DBT and Alcoholics Anonymous. She completed a domestic violence course, an anger management course and attended bereavement counselling.

Ms C also undertook a number of academic courses, including a GNVQ in music and a diploma in specialist body arts. She became a member of the Duke of Edinburgh award scheme and has been involved in performances with the National Youth Theatre. She was a business mentor and gained a business grant from the Prince's Trust for her release. Ms C continued to attend the Buddhist group meetings.

\section{Discussion}

Through DBT Ms C learned how to identify and utilise appropriate skills to help her cope with difficult situations, relationships and her thoughts and emotions more effectively.

This case highlights the considerable progress that can be made with prisoners with a less severe BPD profile and history. When incarcerated at age 19 for manslaughter, 
Ms C was grieving for her father and presented with parasuicidal behaviour, alcohol misuse and anger problems. However, with the support of DBT, Ms C met all her first-stage targets: she stopped her self-injurious behaviour and urges; controlled her anger; and addressed her alcohol misuse and depression. Beyond this she used her skills to further enrich her quality of life with various academic and non-academic pursuits. This positive change is reflected in her psychometric and behavioural data, and improvement which should notably reduce her risk of reconviction. She has effectively learnt to use appropriate skills to gain control over her maladaptive cognitions and emotion dysregulation.

\section{GENERAL DISCUSSION}

The three case studies have illustrated in detail the particular level of challenge faced by professionals delivering DBT in a prison environment. Nee and Farman (2005) described in more general terms the difficulties faced during these prison pilots. These included: hasty implementation of the programme shortly before the Christmas break due to possible funding withdrawal; lack of lead-in time/preparation time for the delivery teams; resistance to the programme by prison staff; unauthorised transfers of participants to other prisons; 50\% DBT delivery team attrition; and 33\% participant attrition. Within this context, we have highlighted the individual pressures on particular participants, as well as the hurdles successfully overcome through skills acquisition and supportive therapy. These have included terminal illnesses, moves to unfamiliar prisons, and distress surrounding family issues. Difficult relationships and frustrating operational procedures inside the prison act as acute stressors during DBT therapy. Therapists and participants alike have worked hard to identify and apply appropriate skills to situations and cope adaptively, with considerable success. This shows that the constraints of the prison environment can be 'radically accepted', and DBT incorporates a very large range of skills which can be effectively tailored to meet needs of individual prisoners. The three case studies indicate the varying preference for different skills depending on stage in therapy, personal circumstance and history with an underlying reliance on core mindfulness, as intended by Linehan (1993a). 
The stabilising effect of core mindfulness skills, with their emphasis on awareness of the moment and identification of mood-states may be the key to success as they result in decreased dissociation and reckless behaviours. Participants then seem capable of learning other types of skills, which naturally reinforce the increasing sense of self and regulation of emotion, which is at the heart of the problem, increasing quality of life. We are in the infancy of understanding which modes or strategies of treatment might be necessary or sufficient for DBT to work however, and future research should focus on this important issue (Robins and Chapman, 2004). The latter authors hypothesise that it is the power of individual therapy with its non-judgmental focus on acceptance and change that may be key. Also unique to DBT is the focus on support of the DBT therapists and emphasis on adherence to DBT, through weekly consultation and external supervision. All therapists involved in the prison pilots saw their involvement with DBT as a life-enhancing practice, which they generalised to many areas of their professional lives. This unique feature may be a critical component of DBT and warrants more attention in future research.

The paper has aimed to describe in detail, the therapeutic process while working with these prisoners. The three cases, varying in levels of childhood trauma, current psychopathology and sentence length have all made significant strides forward in reducing symptomatology, improving quality of life and reducing self-harm. The more entrenched the disorder, the greater the need for longer intervention for particularly severe cases such as Ms A, (Nee and Farman, 2005; Verheul et al, 2003; Low et al, 2001, Linehan, 1993a) who notwithstanding, made notable improvements on a wide range of psychometrics. Given the issues of abandonment surrounding the BPD experience, it is most important that future programmes incorporate adequate support and/or continuing therapy post-programme. Cases B and C, with the help of DBT, began to move beyond addressing the maladaptive cognitions and coping strategies of the past and introduced significantly positive, creative experiences into their lives in the forms of art, drama, sport, spirituality and further education.

Perhaps most importantly in the forensic context, DBT appears effective in reducing criminogenic risk. Notable improvements were seen in the overall borderline syndrome, dissociation, impulsivity, locus of control, self-esteem and suicidal ideation. In the absence of a large randomised controlled trial of DBT it is impossible 
to say with complete confidence that the improvements in these cases were a direct result of DBT and would generalise to a larger population, especially as this was the first time that any of the individuals had received any type of structured, systematic and enduring intervention. However, we feel we have provided more evidence that at least one type of intervention, namely DBT, appears promising as an offending behaviour programme with severely personality-disordered offenders. Only time will tell if DBT has a positive effect on the actual rate of reconviction, or if other interventions could work as well. In turn, we hope our findings will contribute to the growing evidence base on 'what works' with personality disordered prisoners and other offenders with similar profiles. 


\section{References}

Bateman, A. W. \& Fonagy, P. (2004). Mentalisation-based treatment of BPD. Journal of Personality Disorders, 18(1), 36-51.

Bateman, A. W. \& Fonagy, P. (1999). The effectiveness of partial hospitalisation in the treatment of borderline personality disorder - a randomised controlled trial. American Journal of Psychiatry, 156, 1563-1569.

Berzins, L. G. \& Trestman, R. L. (2004). The development and implementation of Dialectical Behaviour Therapy in forensic settings. International Journal of Forensic Mental Health, 3(1), 93-103.

Bloom, B. Owen, B. \& Covington, S. (2004). Women offenders and the gendered effects of public policy. Review of Policy Research, 21(1), 31-48.

Bohus, M., Haaf, B., Stiglmayr, C., Pohl, U., Bohme, R. \& Linehan, M. (2000). Evaluation of inpatient Dialectical Behavioral Therapy for Borderline Personality Disorder - a prospective study. Behaviour Research and Therapy, $38,875-887$.

Coid, J. (1993). An affective syndrome in psychopaths with borderline personality disorder? British Journal of Psychiatry, 162, 641-650.

Department of Corrections (1999). The national study of psychiatric morbidity in New Zealand prisons. Wellington: Government Printing Press. 
Diamond, P. M., Wang, E. W., Holtzer III, C. E., Thomas, C. \& Cruser, dA. (2001). The prevalence of mental illness in prison. Administration and Policy in Mental Health, 29(1), 29-40.

Hayes, S. C., Masuda, A., Bissett, R., Luoma, J. \& Guerrero, L. F. (2004). DBT, FAP and ACT: how empirically oriented are the new behaviour therapy technologies? Behaviour Therapy, 35(1), 35-54

Home Office (2005). Population in custody, March 2005. London: Home Office.

Jones, M. (2001). An indication of prevalence rates of borderline personality disorder amongst female prisoners. Unpublished MSc dissertation.

Koons, C. R., Robins, C. J., Tweed, J. L., Lynch, T.R., Gonzalez, A. M., Morse, J.Q., Bishop, G. K., Butterfield, M. I. \& Bastian, L.A. (2001). Efficacy of Dialectical Behavior Therapy in women veterans with borderline personality disorder. Behavior Therapy 32:371-390.

Linehan, M. M. (1993a). Cognitive Behavioral Treatment of Borderline Personality Disorder. New York: Guilford Press.

Linehan, M. M. (1993b). Skills Training Manual for Treating Borderline Personality Disorder. New York: Guilford Press. 
Linehan, M. M., Armstrong, H.E., Suarez, A., Allmon, D. \& Heard, H.L. (1991). Cognitive-behavioral treatment of chronically parasuicidal borderline patients. Archives of General Psychiatry, 48,1060-1064.

Linehan, M. M., Heard, H. \& Armstrong, H.E. (1993). Naturalistic follow-up of a behavioral treatment for chronically parasuicidal borderline patients. Archives of General Psychiatry, 50, 971-974.

Linehan, M. M., Schmidt, H., Dimeff, L. A., Kanter, J.W., Craft, J. C., Comtois, K.A. \& Recknor, K.L. (1999). Dialectical behavior therapy for patients with borderline personality disorder and drug-dependence. American Journal on Addiction, 8,279-292.

Linehan, M. M., Tutek, D.A., Heard, H. L. \& Armstrong, H. E. (1994). Cognitivebehavioral treatment for chronically parasuicidal borderline patients: Interpersonal Outcomes. American Journal of Psychiatry, 151,1771-1776.

Lipsey, M. (1995). What can we learn from 400 research studies on the effectiveness of treatment with juvenile delinquents? In J. McGuire (Ed.). What Works: Reducing Re-offending: Guidelines from Research and Practice. Chichester: John Wiley \& Sons.

Low, G., Jones, D., Duggan, C., MacLeod, A. \& Power, M. (2001b). Dialectical Behaviour Therapy as a treatment for deliberate self-harm: case studies from a high security psychiatric hospital population. Clinical Psychology and Psychotherapy, 8, 288-300. 
Low, G., Jones, D., Duggan, C., Power, M. \& MacLeod, A. (2001a). The treatment of deliberate self-harm in borderline personality disorder using Dialectical Behaviour Therapy: a pilot study in a high security hospital. Behavioural and Cognitive Psychotherapy, 29, 85-92.

Maden, A., Williams, J., Wong, S. \& Leis, T. (2004). Treating dangerous and severe personality disorder in high security: lessons from the Regional Psychiatric Centre, Saskatoon, Canada. Journal of Forensic Psychiatry and Psychology, 15(3), 375-390.

Nee, C. \& Farman, S. (2005). Female prisoners with borderline personality disorder: some promising treatment developments. Criminal Behaviour and Mental Health. 15, 2-16.

Raine, A. (1993). Features of borderline personality and violence. Journal of Clinical Psychology 49:277-281.

Robinson, D,. Porporino, F. \& Beal, C. (1998). A Review of the Literature on Personal/Emotional Need Factors. Canada: Correctional Service Research Branch.

Roger, D. (1997). Crime and Emotion Control. In J. Hodge, M. McMurran \& Hollin C. (Eds). Addicted to Crime? Chichester: Wiley. 
Ross, R.R, \& Fabiano, E. A. (1985). Time to think. A cognitive behavioural model of delinquency prevention and offender rehabilitation. Tennessee: Johnson City.

Ryle, A. (2004). The contribution of Cognitive Analytic Therapy to the treatment of borderline personality disorder. Journal of Personality Disorders, 18(1), 3-35.

Ryle, A. (1997). Cognitive Analytic Therapy and borderline personality disorder: the model and the method. Chichester: Wiley.

Singleton, N., Meltzer, H., Gatward, R., Coid, J. \& Deasy, D. (1998). Psychiatric morbidity among prisoners in England \& Wales: A survey carried out in 1997 by the social survey dimension of ONS on behalf of the Department of Health. London: HMSO.

Sly, A. \& Taylor, K. (2003). Preliminary evaluation of Dialectical behaviour Therapy within a women' structured living environment. Canada: Correctional Service.

Tyrer, P., Tom, B., Byford, S., Schmidt, U., Jones, V., Davidson, K., Knapp, M., MacLeod, A, \& Catalan, J. (2004). Differential effects of manual assisted Cognitive Behaviour Therapy in the treatment of recurrent deliberate selfharm and personality disturbance: the Popmact study. Journal of Personality Disorder, 18(1), 102-116. 
Verheul, R., Van den Bosch, L.M.C., Koeter, M.W.J., de Ridder, M.A.J., Stijnen, T. \& Van den Brink, W. (2003). Dialectical behaviour therapy for women with borderline personality disorder. British Journal of Psychiatry, 182:135-140.

Walters, G.D., \& White, T.W. (1989). The thinking criminal: A cognitive model of lifestyle criminality. Criminal Justice Research Bulletin 4:4.

Warren. F., McGauley, G., Norton, K., Dolan, B., Preedy-Fayers, K., Pickering, A. \& Geddes, J.R. (2003). Review of treatments for severe personality disorder (Report No. 30/03). Home Office Online Report. 
Table 1: Psychometric Assessment Scores for Ms A showing improvement ( $\downarrow \downarrow$ indicates desired direction of change)

\begin{tabular}{|c|c|c|c|c|}
\hline $\begin{array}{l}\text { Psychometric Test } \\
\text { (maximum score) }\end{array}$ & $\begin{array}{l}\text { Time } 1 \\
\text { Pre-DBT }\end{array}$ & $\begin{array}{l}\text { Time } 2 \\
\text { Mid-DBT }\end{array}$ & $\begin{array}{l}\text { Time } 3 \\
\text { Post-DBT }\end{array}$ & $\begin{array}{l}\text { Time } 4 \\
6 \mathrm{~m} \text { Post-DBT }\end{array}$ \\
\hline $\begin{array}{l}\text { Borderline } \\
\text { Syndrome Index } \\
(52) \downarrow\end{array}$ & 29 & 14 & 15 & 12 \\
\hline $\begin{array}{l}\text { Dissociative } \\
\text { Experiences (100) } \\
\downarrow\end{array}$ & 28.64 & 7.61 & 8.86 & 2.75 \\
\hline $\begin{array}{l}\text { Impulsiveness } \\
\text { (22) } \downarrow\end{array}$ & 13 & 10 & 5 & 3 \\
\hline $\begin{array}{l}\text { Locus of Control } \\
\text { (72) } \uparrow\end{array}$ & 39 & 48 & 52 & 60 \\
\hline $\begin{array}{l}\text { Self-Esteem (40) } \\
\uparrow\end{array}$ & 20 & 26 & 24 & 31 \\
\hline $\begin{array}{l}\text { State Anger (60) } \\
\downarrow\end{array}$ & 32 & 34 & 29 & 19 \\
\hline $\begin{array}{l}\text { Survival and } \\
\text { Coping Beliefs } \\
\text { (6) } \uparrow\end{array}$ & 2.46 & 3.58 & 3.75 & 4.5 \\
\hline $\begin{array}{l}\text { Emotion Control } \\
\text { Questionnaire } \\
\text { (ECQ) - } \\
\text { Rehearsal (14) } \downarrow\end{array}$ & 8 & 7 & 4 & 2 \\
\hline
\end{tabular}

Figure 1: Self-Injurious Data from Pre to Six-Months Post-DBT for Ms A

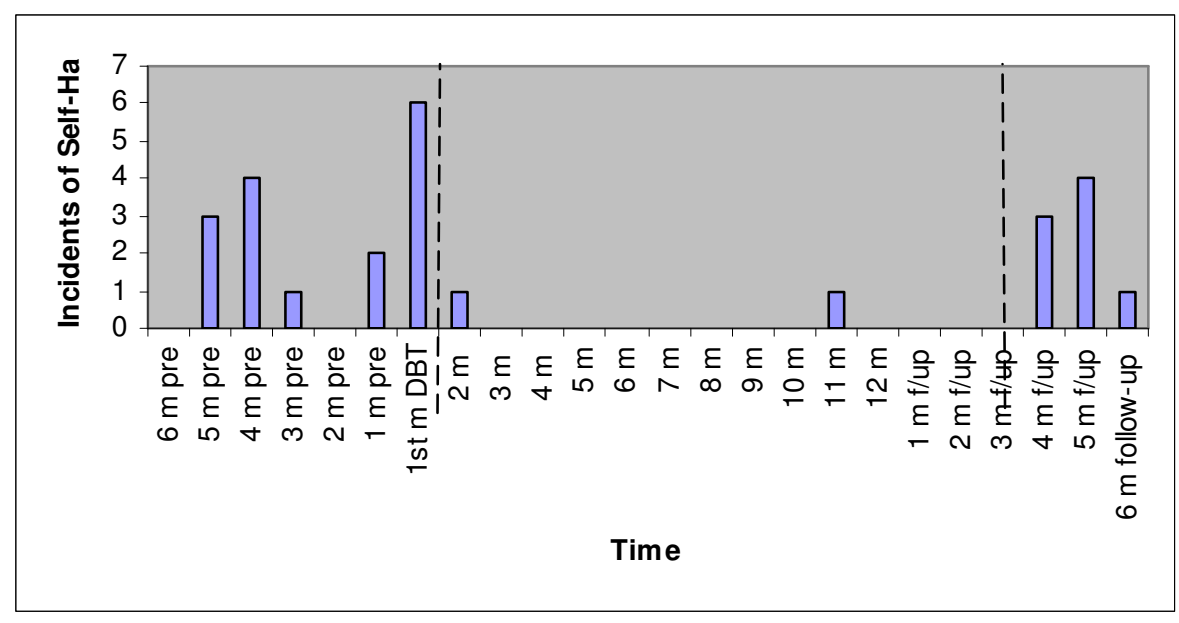


Table 2: Assessment Scores for Ms B

(N.B. $\uparrow \downarrow$ indicate desired direction of change)

\begin{tabular}{|c|c|c|c|c|}
\hline $\begin{array}{l}\text { Psychometric } \\
\text { Test } \\
\text { (maximum } \\
\text { score) }\end{array}$ & $\begin{array}{l}\text { Time } 1 \\
\text { Pre-DBT }\end{array}$ & $\begin{array}{l}\text { Time } 2 \\
\text { Mid-DBT }\end{array}$ & $\begin{array}{l}\text { Time } 3 \\
\text { Post-DBT }\end{array}$ & $\begin{array}{l}\text { Time } 4 \\
6 \mathrm{~m} \text { Post-DBT }\end{array}$ \\
\hline $\begin{array}{l}\text { Borderline } \\
\text { Syndrome Index } \\
\text { (52) } \downarrow\end{array}$ & 0 & 18 & 2 & 4 \\
\hline $\begin{array}{l}\text { Dissociative } \\
\text { Experiences } \\
(100) \downarrow\end{array}$ & 21.07 & 70.39 & 8.82 & 8.68 \\
\hline $\begin{array}{l}\text { Impulsiveness } \\
\text { (22) } \downarrow\end{array}$ & 2 & 1 & 1 & 0 \\
\hline $\begin{array}{l}\text { Locus of } \\
\text { Control (72) } \uparrow\end{array}$ & 53 & 51 & 57 & 54 \\
\hline $\begin{array}{l}\text { Self-Esteem } \\
(40) \uparrow\end{array}$ & 30 & 28 & 39 & 30 \\
\hline $\begin{array}{l}\text { State Anger (60) } \\
\downarrow\end{array}$ & 15 & 15 & 15 & 15 \\
\hline $\begin{array}{l}\text { Trait Anger (40) } \\
\downarrow\end{array}$ & 10 & 28 & 13 & 17 \\
\hline $\begin{array}{l}\text { Survival and } \\
\text { Coping Beliefs } \\
\text { (6) } \uparrow\end{array}$ & 6 & 4.83 & 5.67 & 4 \\
\hline
\end{tabular}

Figure 2: Self-Injurious Data from Pre to Six-Months Post-DBT for Ms B

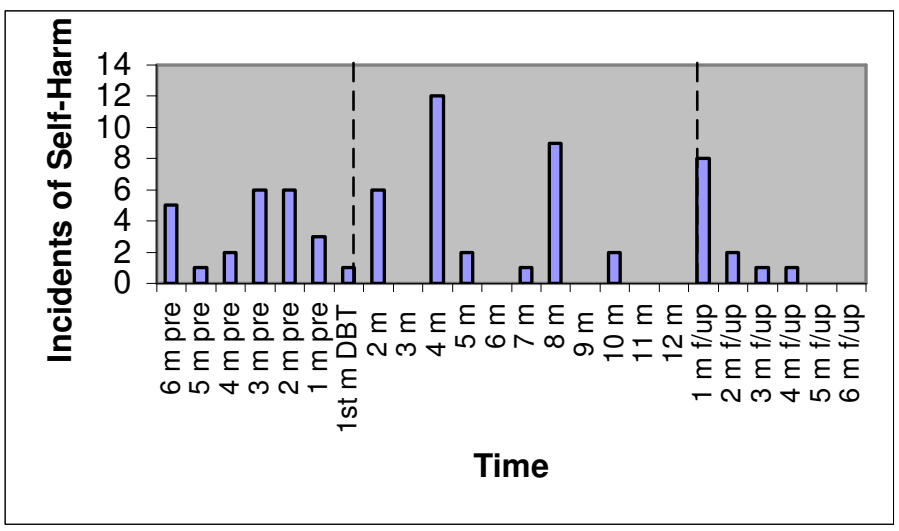


Table 3: Assessment Scores for Ms C

(N.B. $\uparrow \downarrow$ indicate desired direction of change)

\begin{tabular}{|c|c|c|c|c|}
\hline $\begin{array}{l}\text { Psychometric } \\
\text { Test } \\
\text { (maximum } \\
\text { score) }\end{array}$ & $\begin{array}{l}\text { Time } 1 \\
\text { Pre-DBT }\end{array}$ & $\begin{array}{l}\text { Time } 2 \\
\text { Mid-DBT }\end{array}$ & $\begin{array}{l}\text { Time } 3 \\
\text { Post-DBT }\end{array}$ & $\begin{array}{l}\text { Time } 4 \\
6 \mathrm{~m} \text { Post-DBT }\end{array}$ \\
\hline $\begin{array}{l}\text { Borderline } \\
\text { Syndrome Index } \\
(52) \downarrow\end{array}$ & 17 & 0 & 0 & 0 \\
\hline $\begin{array}{l}\text { Dissociative } \\
\text { Experiences } \\
(100) \downarrow\end{array}$ & 19.46 & 3.68 & 0.25 & 0.54 \\
\hline $\begin{array}{l}\text { Impulsiveness } \\
\text { (22) } \downarrow\end{array}$ & 17 & 3 & 4 & 3 \\
\hline $\begin{array}{l}\text { Locus of } \\
\text { Control (72) } \uparrow\end{array}$ & 50 & 65 & 70 & 70 \\
\hline $\begin{array}{l}\text { Self-Esteem } \\
(40) \uparrow\end{array}$ & 20 & 30 & 38 & 35 \\
\hline $\begin{array}{l}\text { State Anger (60) } \\
\downarrow\end{array}$ & 16 & 16 & 16 & 15 \\
\hline $\begin{array}{l}\text { Trait Anger (40) } \\
\downarrow\end{array}$ & 14 & 11 & 10 & 12 \\
\hline $\begin{array}{l}\text { Survival and } \\
\text { Coping Beliefs } \\
\text { (6) } \uparrow\end{array}$ & 3.42 & 5.88 & 5.71 & 5.63 \\
\hline
\end{tabular}

Figure 3: Self-Injurious Data from Pre to Six-Months Post-DBT for Ms C

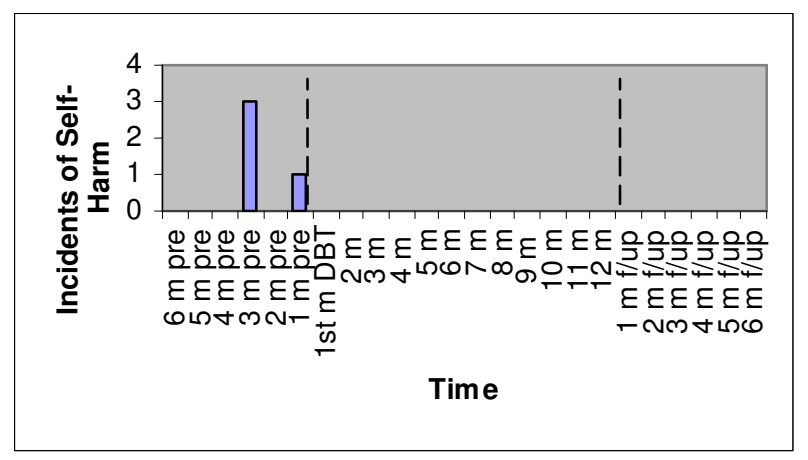


1. Including unstable relationships, chronic para-suicidal and suicidal behaviour, difficulties with intense anger, impulsive and self-damaging behaviour, and emotional instability.

2. Four pilots of DBT are being undertaken in custodial settings in Canada but quantitative outcomes are yet to be published.

3. This is a UK committee involving the Department of Health, Home Office and Prison Service Headquarters. 'Dangerous and Severe Personality Disorder' is a working definition describing a group of individuals who, because of their disorder, may pose a significant risk of serious harm to others. The programme's aim is to develop policies to identify, treat, manage and reduce the criminogenic risk of this group. Treatments for Borderline Personality Disorder comprised the largest group cited in the review.

4. Effect sizes ranged from 0.40 to 0.61 .

5. 'The capacity to think about oneself in relation to others and to understand others' state of mind' (Bateman and Fonagy, 1999, p.1565).

6. Up to six one-to-one sessions should occur pre-DBT to prepare the participant for group work, diary cards, chain analyses etc.

7. Stages 2 and 3 of DBT deal with post-traumatic stress and self-esteem/ individual treatment goals consecutively and can take many years to complete, given the entrenched nature of the disorder.

8. Messages left on the answerphone were responded to that day in the vast majority of cases and participants were aware of this.

9. These are also standard measures used in UK government evaluations of offending behaviour programmes undertaken by Offending Behaviour Programmes Unit at Prison Service HQ because of their links with criminogenic risk.

10. Offences against prison discipline.

11. Observe and describe are skills from the core mindfulness module. 'Observe' involves simply noticing experiences, without getting caught in the experience and without reacting to the experience. Describe involves putting words on the experience to acknowledge the experience (e.g. "stomach muscles tightening") and putting experiences into words, so describing what is happening, putting a name on the feelings, but without getting caught in an emotional reaction to content.

12. Only notable improvements are included for reasons of space.

13. Her overall profile of self-harm had included setting fires, burning herself and swallowing razors as well as cutting. Post DBT the majority of her self-harm was confined to superficial cutting.

14. Ms B was assessed by the prison education department as dyslexic and also as having literacy and numeracy skills that were below average, leading to outbursts when she was finding DBT difficult. Ms B also had angry outbursts over her BPD diagnosis, as she disliked being labelled.

15. Ms B had low concentration levels leading to hyperactivity.

16. PLEASE MASTER is a set of skills that involves taking care of your body (through treating PhysicaL illness, balancing Eating, avoiding mood-Altering

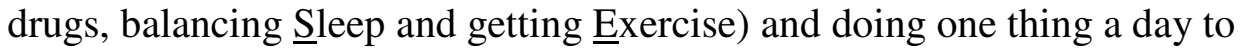
make yourself feel competent and in control (building MASTERy).

17. One-mindfully is a 'taking hold of your mind 'how' skill' in which you do one thing at a time, let go of distractions and concentrate your mind. 
18. Another 'taking hold of your mind: "how" skill'. Using non-judgementally you have to: see but don't evaluate, unglue your opinions from the facts, accept each moment, acknowledge but don't judge and when you find yourself judging, don't judge your judging. 